\title{
Emotion
}

\section{A Nationally Representative Study of Emotional Competence and Health}

Moïra Mikolajczak, Hervé Avalosse, Sigrid Vancorenland, Rebekka Verniest, Michael Callens, Nady van Broeck, Carole Fantini-Hauwel, and Adrien Mierop

Online First Publication, April 20, 2015. http://dx.doi.org/10.1037/emo0000034

CITATION

Mikolajczak, M., Avalosse, H., Vancorenland, S., Verniest, R., Callens, M., van Broeck, N., Fantini-Hauwel, C., \& Mierop, A. (2015, April 20). A Nationally Representative Study of Emotional Competence and Health. Emotion. Advance online publication.

http://dx.doi.org/10.1037/emo0000034 


\title{
A Nationally Representative Study of Emotional Competence and Health
}

\author{
Moïra Mikolajczak \\ Université catholique de Louvain
}

\author{
Hervé Avalosse, Sigrid Vancorenland, \\ Rebekka Verniest, and Michael Callens \\ Mutualité Chrétienne-Christelijke Mutualiteit, Belgium
}

\author{
Nady van Broeck \\ University of Leuven
}

\author{
Carole Fantini-Hauwel \\ Université Libre de Bruxelles
}

\author{
Adrien Mierop \\ Université catholique de Louvain
}

\begin{abstract}
Emotional competence (EC; also called "emotional intelligence"), which refers to individual differences in the identification, understanding, expression, regulation, and use of one's emotions and those of others, has been found to be an important predictor of individuals' adaptation to their environment. Higher EC is associated with greater happiness, better mental health, more satisfying social and marital relationships, and greater occupational success. Whereas a considerable amount of research has documented the significance of EC, 1 domain has been crucially under investigated: the relationship between EC and physical health. We examined the relationship between EC and objective health indicators in 2 studies $\left(N_{1}=1,310 ; \mathrm{N}_{2}=9,616\right)$ conducted in collaboration with the largest Mutual Benefit Society in Belgium. These studies allowed us (a) to compare the predictive power of EC with other well-known predictors of health such as age, sex, Body Mass Index, education level, health behaviors (diet, physical activity, smoking and drinking habits), positive and negative affect, and social support; (b) to clarify the relative weight of the various EC dimensions in predicting health; and (c) to determine to what extent EC moderates the effect of already known predictors on health. Results show that EC is a significant predictor of health that has incremental predictive power over and above other predictors. Findings also show that high EC significantly attenuates (and sometimes compensates for) the impact of other risk factors. Therefore, we argue that EC deserves greater interest and attention from health professionals and governments.
\end{abstract}

Keywords: emotional competencies, emotional intelligence, emotional skills, emotion regulation, emotion identification

Supplemental materials: http://dx.doi.org/10.1037/emo0000034.supp

Although we all experience and witness all sorts of emotions throughout our lives, we markedly differ in the extent to which we identify, express, understand, regulate, and use our own and others' emotions (Mayer \& Salovey, 1997; Mikolajczak, Quoidbach, Kotsou, \& Nelis, 2009; Petrides \& Furnham, 2003). The concept of emotional competence (EC) — alternately labeled "emotional intelligence" (EI or trait EI) or "emotional skills"- has been proposed to account for this idea. Although the term "EI" is more common to designate these individual differences, we prefer the term EC because it is more consistent with recent results (Kotsou, Nelis, Grégoire, \& Mikolajczak, 2011; Nelis et al., 2011) that show that these competences can be taught and learned (unlike intelligence).

Individuals with high EC are able to identify their emotions as well as those of others, express them in a socially acceptable manner, understand their causes and consequences, regulate them
Moïra Mikolajczak, Department of Psychology, Université catholique de Louvain; Hervé Avalosse, Sigrid Vancorenland, Rebekka Verniest, Michiel Callens, Research and Development Department, Mutualité Chrétienne-Christelijke Mutualiteit, Belgium; Nady Van Broeck, Department of Psychology, University of Leuven; Carole Fantini-Hauwel, Department of Psychology, Université Libre de Bruxelles; Adrien Mierop, Department of Psychology, Université catholique de Louvain.

C. Fantini-Hauwel and A. Mierop have equally contributed to this study.
This study was funded by the Belgian American Educational Foundation (BAEF) Alumni Award, 2012. The authors thank Ilios Kotsou who set up the first contact between the University and the Mutualite Chrétienne-Christelijke Mutualiteit and who made this collaboration possible. The authors also thank him for his advice on the measures of Study 1. We also thank Cécile Husquet for proofreading the manuscript.

Correspondence concerning this article should be addressed to Moïra Mikolajczak, Department of Psychology, Université catholique de Louvain, Place Cardinal Mercier 10, 1348 Louvain-la-Neuve, Belgium. E-mail: moira.mikolajczak@uclouvain.be 
when they are not appropriate to the context or to their goals, and use them to enhance thoughts and actions (Mayer \& Salovey, 1997). While those individuals are able to take advantage of emotions without letting the latter lead them astray, individuals with low EC have a hard time taking into account the information emotions convey and are commonly overwhelmed by them (see Mikolajczak, Quoidbach, Kotsou, \& Nelis, 2009 for a review).

Past debates on the status of EC as intelligence (i.e., is EC an ability?) or trait (i.e., is EC a disposition?) have given birth to a tripartite model of EC (see Mikolajczak, Petrides, Coumans, \& Luminet, 2009). Briefly, this model posits three levels of EC: knowledge, abilities, and traits. The knowledge level refers to what people know about emotions and emotional competencies (e.g., Do I know how to express my emotions constructively?). The ability level refers to the ability to apply this knowledge in an emotional situation (e.g., Am I able to express my emotions constructively?). The focus here is not on what people know but on what they can do. For instance, even though many people know that they should not shout when angry, many are simply unable not to do so. The trait level refers to emotion-related dispositions, namely, the propensity to behave in a certain way in emotional situations (Do I typically express my emotions in a constructive manner?). The focus here is not on what people know or on what they are able to do, but on what they typically do. For instance, some individuals might be able to express their emotion constructively if explicitly asked to do so, but they do not manage this spontaneously. These three levels of EC are loosely connected: knowledge does not always translate into ability, which, in turn, does not always translate into usual behavior.

The literature indicates that the trait level of EC, on which we will focus in this article, has a considerable impact on psychological, social, and work adjustment. At a psychological level, higher EC is for instance associated with increased well-being (e.g., Austin, Saklofske, \& Egan, 2005) as well as with decreased psychological disorders (e.g., Petrides, Pérez-González, \& Furnham, 2007). At a social level, higher EC leads to more satisfying social and marital relationships (e.g., Schutte et al., 2001). Workwise, EC has been found to be associated with superior academic achievement and higher job performance (Petrides, Frederickson, \& Furnham, 2004; see O'Boyle, Humphrey, Pollack, Hawver, \& Story, 2011 for a meta-analysis). As shown by Nelis et al. (2011) and Kotsou et al. (2011), emotional competence is causally involved in the above outcomes: when EC is enhanced through training, psychological, social, and work adjustment improve. It is noteworthy that the relationship between EC and indicators of adjustment is not only statistically significant but that it is also practically meaningful. For instance, a nurse with high EC is three times less likely to suffer burnout than a nurse with low EC (Mikolajczak, Menil, \& Luminet, 2007). Likewise, a person with high EC is more likely to be chosen as a romantic partner than a person with low EC (Schutte et al., 2001).

Whereas a considerable amount of research has shown the importance of EC, one domain has been crucially under investigated: the relationship between EC and physical health. Although there is a profusion of research on EC and subjective health (see Schutte et al., 2007 and Martins, Ramalho, \& Morin, 2010 for meta-analyses), there is a dearth of research that uses objective indicators of health status. All studies published so far rely on self-reported criteria. However, there is converging evidence that there might be a true relationship between EC and health. First, EC has been shown to impact cortisol secretion in stressful situations (Mikolajczak, Roy, Luminet, Fillée, \& de Timary, 2007). If we consider the number of stressors one faces during a lifetime along with the ubiquitous functions of cortisol in the body, the accumulation of these differences in cortisol secretion may ultimately lead to different profiles of inflammation (see Tillmann, Krishnadas, Cavanagh, \& Petrides, 2013) and different somatic health states. Second, EC is negatively related to substance abuse like tobacco, marijuana, or alcohol (e.g., Riley \& Schutte, 2003), all of which all have well-known deleterious effects on health. Third, EC is inversely related to deliberate self-harm (Mikolajczak, Petrides, \& Hurry, 2009), which is a cause of injury and infection. Fourth, EC has been shown to decrease risky behaviors such as reckless driving (Brackett, Mayer, \& Warner, 2004), which cause accidents and injury.

In view of the above, the goal of the current study was to examine the relationship between EC and objective health indicators. Study 1 examined this in a sample of 1,310 members of the largest Mutual Benefit Society in Belgium. It also aimed to compare the predictive power of EC with other well-known predictors of health such as age, sex, Body Mass Index (BMI), education level, health behaviors (diet, physical activity, smoking, and drinking habits), positive and negative affectivity, and social support. Study 2 aimed to replicate the results among 9,616 other members of the same Mutual Benefit Society as well as to clarify the relative weight of the various EC dimensions in predicting health. It also sought to determine which variables, if any, mediate the relationship between EC and health. Finally, we examined to what extent EC moderates the effect of already known predictors on health.

\section{Method}

Both studies were approved by the Internal Ethical Committee and conducted in accordance with the guidelines provided by the law department of the Mutual Benefit Society.

\section{Study 1}

Participants and procedure. A stratified sample of 10,000 adults (between 18 and 80 years old) drawn from the database of the largest Mutual Benefit Society in Belgium (i.e., the Mutualité Chrétienne-Christelijke Mutualiteit, abbreviated as MC-CM) was contacted by mail by the MC-CM and invited to complete a Survey on emotions and health. The sample was stratified on gender, age, socioeconomic status, and province to be as representative as possible of the Belgian population. Among this sample, 1,646 subjects $(16 \%)$ answered the whole questionnaire and gave their consent for coupling it with the health data in possession of the MC-CM. Among this sample, 1,310 subjects (13\%) were members of the MC-CM for the whole period under study (2000-2011). The final sample consisted in these 1,310 subjects $\left(M_{\text {age }}=51.2, S D=\right.$ $16.1 ; 58 \%$ female). As can be seen in Supplementary Table 2, women and seniors are overrepresented in the final sample. How- 
ever, it is nearly fully representative of the Belgian population regarding province repartition and SES.

\section{Measures.}

Demographics. Participants were asked to indicate their province, age, sex, education level (primary school, junior high school, high school, college, university [master], or postgraduate [Ph.D., MBA]), marital status (single, in a relationship, divorced/separated, or widowed), number of children, type of occupation if applicable (temporary worker, worker, employee, state employee, or freelancer), status if they do not have a job (housewife/househusband, student, retired, unemployed, or disabled), height and weight (to compute their BMI).

$\boldsymbol{E C}$ was assessed using the Trait Emotional Intelligence Questionnaire-Short Form (TEIQue-SF). This measure comprises 30 7-point items (from strongly agree to strongly disagree) providing a global EC score. The TEIQue shows excellent psychometric properties (see Cooper \& Petrides, 2010). In this study, the internal consistency $(\alpha)$ of the scale was .89. Examples of items are "Expressing my emotions is not a problem for me" and "When I am sad, I find it easy to cheer myself up."

Trait Positive Emotions were measured using 10 items rated on a 5-point scale (ranging from never to very often): interested, pleased, happy, enthusiastic, joyful, proud, amazed, serene, grateful, and amused. This scale was developed for the purpose of the present study and is adapted from the PANAS-PA (Watson, Clark, \& Tellegen, 1988) where interested, enthusiastic and proud were kept, and excited, strong, alert, inspired, attentive, and active- that are indicators of activation rather than discrete positive emotions per se (see Barrett \& Russell, 1999)-were replaced by discrete positive emotions (the focus of this study was on emotion valence-positive vs. negative-rather than emotional activation). The internal consistency $(\alpha)$ of the scale was .85 .

Trait Negative Emotions were evaluated using 11 items rated on a 5-point scale (ranging from never to very often): anxious, angry, guilty, jealous, furious, annoyed, ashamed, nervous, sad, fearful, or stressed. As in the PANAS-NA (Watson, Clark, \& Tellegen, 1988), the scale contains items covering each of the following basic negative emotions: anger, fear, sadness, shame, and guilt, to which we added the emotion of jealousy. The internal consistency $(\alpha)$ of the scale was .86 .

Social support was appraised via two items targeting emotional and tangible support, respectively (e.g., How many people-including possibly your relatives-can you count on for . . .). The scale was created for the purpose of the current study and inspired by the sample items found in Sarason, Levine, Basham, and Sarason (1983, p. 129). The internal consistency $(\alpha)$ of the scale was .80 .

Health behaviors were assessed using 10 items of the 13-item questionnaire used by the Public Health Institute in Belgium (three items were removed because they were related to emotion management and were redundant with the EC questionnaire). Four items measured diet habits ( $\alpha=.70$; sample item: I avoid eating too much salt by cooking with a limited quantity of salt and by avoiding adding salt during dinner. I avoid salty snacks (like crisps); the higher the score, the better the habits), three measured exercising habits $(\alpha=$ .61; sample item: I do sport (e.g., running, swimming, aerobic ...) for 15 to $30 \mathrm{~min}$ at least three times a week; the higher the score, the higher the physical activity), one smoking habits (I smoke more than 2 cigarettes a day), and one drinking habits (I drink at least two

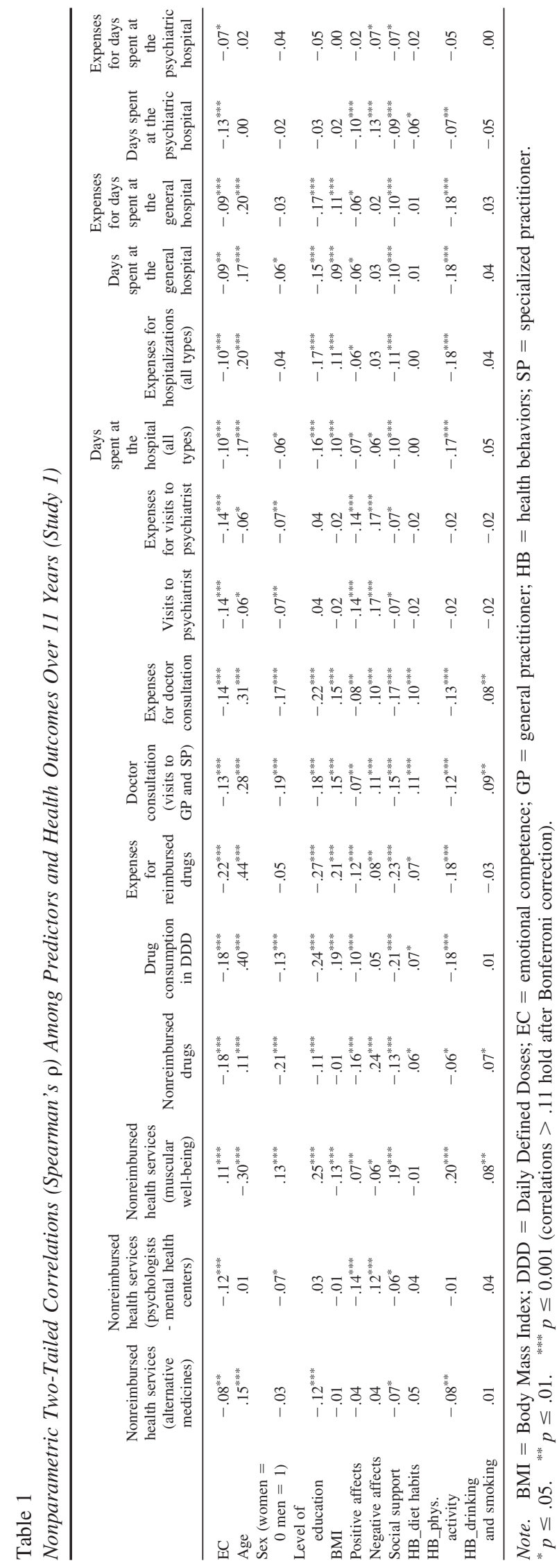


Table 2

Regressions ("Enter Approach") Testing the Incremental Predictive Power of EC Regarding Health, Over and Above the Other Predictors (Study 1)

\begin{tabular}{|c|c|c|c|c|c|c|c|c|}
\hline & $\begin{array}{c}\text { Nonreimbursed } \\
\text { health } \\
\text { services } \\
\text { (alternative } \\
\text { medicines) }\end{array}$ & $\begin{array}{l}\text { Nonreimbursed } \\
\text { health serv. } \\
\text { (psychologists } \\
\text { - mental } \\
\text { health } \\
\text { centers) }\end{array}$ & $\begin{array}{l}\text { Nonreimbursed } \\
\text { health } \\
\text { services } \\
\text { (muscular } \\
\text { well-being) }\end{array}$ & $\begin{array}{c}\text { Nonreimbursed } \\
\text { drugs }\end{array}$ & $\begin{array}{l}\text { Drug } \\
\text { consumption } \\
\text { in DDD }\end{array}$ & $\begin{array}{l}\text { Expenses for } \\
\text { reimbursed } \\
\text { drugs }\end{array}$ & $\begin{array}{c}\text { Doctor } \\
\text { consultation } \\
\text { (visits to GP } \\
\text { and SP) }\end{array}$ & $\begin{array}{l}\text { Expenses for } \\
\text { doctor } \\
\text { consultation }\end{array}$ \\
\hline $\begin{array}{l}\text { Model with all } \\
\text { other } \\
\text { predictors } \\
\text { but EC }\end{array}$ & $\begin{array}{l}F(8,1116)= \\
1.76 ; p= \\
\quad .08\end{array}$ & $\begin{array}{c}F(8,1116)= \\
3.60 ; p< \\
.001\end{array}$ & $\begin{array}{c}F(8,1116)= \\
23.73 ; p< \\
.001\end{array}$ & $\begin{array}{c}F(8,1177)= \\
14.8 ; p< \\
.001\end{array}$ & $\begin{array}{c}F(8,1178)= \\
24.00 ; p< \\
.001\end{array}$ & $\begin{array}{c}F(8,1178)= \\
3.21 ; p< \\
\quad .001\end{array}$ & $\begin{array}{c}F(8,1178)= \\
24.91 ; p< \\
.001\end{array}$ & $\begin{array}{c}F(8,1178)= \\
25.47 ; p< \\
.001\end{array}$ \\
\hline $\begin{array}{l}\text { Incremental } \\
\text { model } \\
\text { with EC }\end{array}$ & $\begin{array}{l}F(1,1115)= \\
0.80 ; p= \\
\text { ns }\end{array}$ & $\begin{array}{c}F(1,1115)= \\
36.71 ; p< \\
.001\end{array}$ & $\begin{array}{l}F(1,1115)= \\
0.18 ; p= \\
\mathrm{ns}\end{array}$ & $\begin{array}{c}F(1,1176)= \\
35.55 ; p< \\
.001\end{array}$ & $\begin{array}{c}F(1,1177)= \\
10.66 ; p< \\
.001\end{array}$ & $\begin{array}{c}F(1,1177)= \\
4.95 ; p< \\
.05\end{array}$ & $\begin{array}{l}F(1,1177)= \\
5.00 ; p< \\
.05\end{array}$ & $\begin{array}{c}F(1,1177)= \\
8.52 ; p< \\
.01\end{array}$ \\
\hline \multicolumn{9}{|l|}{$\beta$ s for } \\
\hline Age & -.02 & $-.11^{* * * *}$ & $-.17^{* * * * *}$ & $.11^{* *}$ & $.22^{* * * *}$ & $.07 \dagger$ & $.22^{* * * * *}$ & $.22^{* * * *}$ \\
\hline Sex & $.08^{*}$ & $.09^{* * *}$ & $.12^{* * * * *}$ & $.25^{* * * *}$ & $.07^{* * *}$ & -.03 & $.19^{* * * *}$ & $.17^{* * * * *}$ \\
\hline Education & -.05 & $.06 \dagger$ & $.10^{* * *}$ & -.02 & $-.07^{*}$ & -.04 & $-.06^{*}$ & $-.09^{* *}$ \\
\hline BMI & -.01 & .04 & -.03 & .03 & $.12^{* * * *}$ & .00 & $.10^{* * * * *}$ & $.10^{* * * * *}$ \\
\hline Soc.Sup. & .00 & -.03 & .06 & $-.07^{*}$ & $-.07^{*}$ & -.01 & $-.06^{*}$ & $-.07^{*}$ \\
\hline Diet Hab. & .05 & .04 & .00 & .05 & .01 & .01 & .04 & .04 \\
\hline Phys. Act & .04 & $.06 \dagger$ & $.18^{* * * *}$ & $.07^{*}$ & $-.07^{*}$ & -.05 & -.05 & -.04 \\
\hline Tob. Alc. & .02 & -.03 & .03 & -.04 & -.02 & -.02 & $.05 \dagger$ & .04 \\
\hline EC & -.03 & $-.20^{* * * *}$ & .01 & $-.19^{* * * *}$ & $-.10^{* * * *}$ & $-.07^{*}$ & $-.07^{*}$ & $-.09^{* * *}$ \\
\hline
\end{tabular}

Note. $\quad$ DDD $=$ Daily Defined Doses; BMI $=$ Body Mass Index; Diet Hab. $=$ diet habits; $\mathrm{EC}=$ emotional competence; GP $=$ general practitioner; Phys Act. $=$ physical activity; Sos.Sup. $=$ social support; $\mathrm{SP}=$ specialized practitioner; Tob. Alc. $=$ tobacco and alcohol habits. See the online only version of Table 2 in its entirety in the supplemental materials.

${ }^{a}$ See last row of the Table to see the list of predictors entered in the model.

${ }^{\dagger} p \leq .10 .{ }^{*} p \leq .05$. ${ }^{* *} p \leq .01$. ${ }^{* * *} p \leq .001$.

glasses of alcoholic beverages a day). All items are rated on a 3-point Likert-scale (nearly never, sometimes, or nearly always). The internal consistency $(\alpha)$ of the global scale was .64 .

Consumption of nonreimbursed health-related services. Participants were asked to report on a 5-point Likert scale (never, less than once a year, once or twice a year, three to five times a year, or more than five times a year) the frequency of their visits to psychologists, mental health centers, balneotherapy centers, acupuncturists, osteopaths, chiropractors, masseurs, aromatherapists, energytherapists, or healers. Factor analysis revealed three factors that we named "alternative medicine" (comprising aromatherapists, acupuncturists, chiropractors, healers, and energytherapists), "psychologists and mental health centers" (comprising psychologists and mental health centers), and "muscular well-being" (comprising balneotherapy centers, masseurs, osteopaths, and energytherapists). ${ }^{1}$ Note that the consumption of these services seems to be poorly correlated, with $\alpha$ s of $.41, .39$ and .54 for the three factors, respectively.

Consumption of nonreimbursed drugs. Participants were asked to report on a 5-point Likert scale (never, rarely, several times a month, several times a week, or nearly every day) the frequency with which they take painkillers, muscle cream, sleeping pills, vitamins and food supplements, homeopathic treatment, or alternative medicines (e.g., medicinal plants). As these items were not expected to show high internal consistency, no $\alpha$ was computed.

Objective health care consumption. Participants' consent for coupling the data allowed us to retrieve the following information from the MC-CM records for each respondent over the last 11 years: number of visits to doctors (general practitioners and specialists), number of days spent in hospitals (by type of hospital), and the
Defined Daily Dose (DDD), a typical indicator of medication consumption based on the average maintenance dose per day (DDD were obtained separately for each class of the Anatomical Therapeutic Chemical [ATC] Classification System). Finally, we also obtained the total cost (in euros) to the Belgian government for each of these expenses.

Results and discussion. Table 1 presents the correlations between the various health predictors and both self-reported and objective health outcomes. ${ }^{2}$ As shown in this table, with the exception of tobacco and alcohol use, whose predictive power is lower than expected, all other predictors (i.e., age, sex, education, BMI, PA, NA, social support, diet habits, and physical activity habits) are significantly related to drug and health care consumption. Note that diet habits do not always correlate in the expected way and do not predict drug consumption after Bonferroni correction for multiple comparisons. However, globally, our study fully replicates previous studies showing the importance of each of these variables regarding health (for age, see Repetto \& Audisio, 2006 for review; for sex, see, e.g., Bertakis, Azari, Helms, Callahan, \& Robbins, 2000; for education, see Adler et al., 1994 for review; for BMI, see, e.g., Stevens et al., 1998; for PA, see Pressman \& Cohen, 2005 for review; for NA see, e.g., Suls \& Bunde, 2005; for social support, see Uchino, 2006 for review; for physical activity, see Warburton, Nicol, \& Bredin, 2006 for

\footnotetext{
${ }^{1}$ Energytherapists loaded equally on the first and third factors.

${ }^{2}$ Because of the number of tables included in this article, correlations among the various predictors are presented in Table 1 of the supplementary material.
} 
Table 2 (continuing)

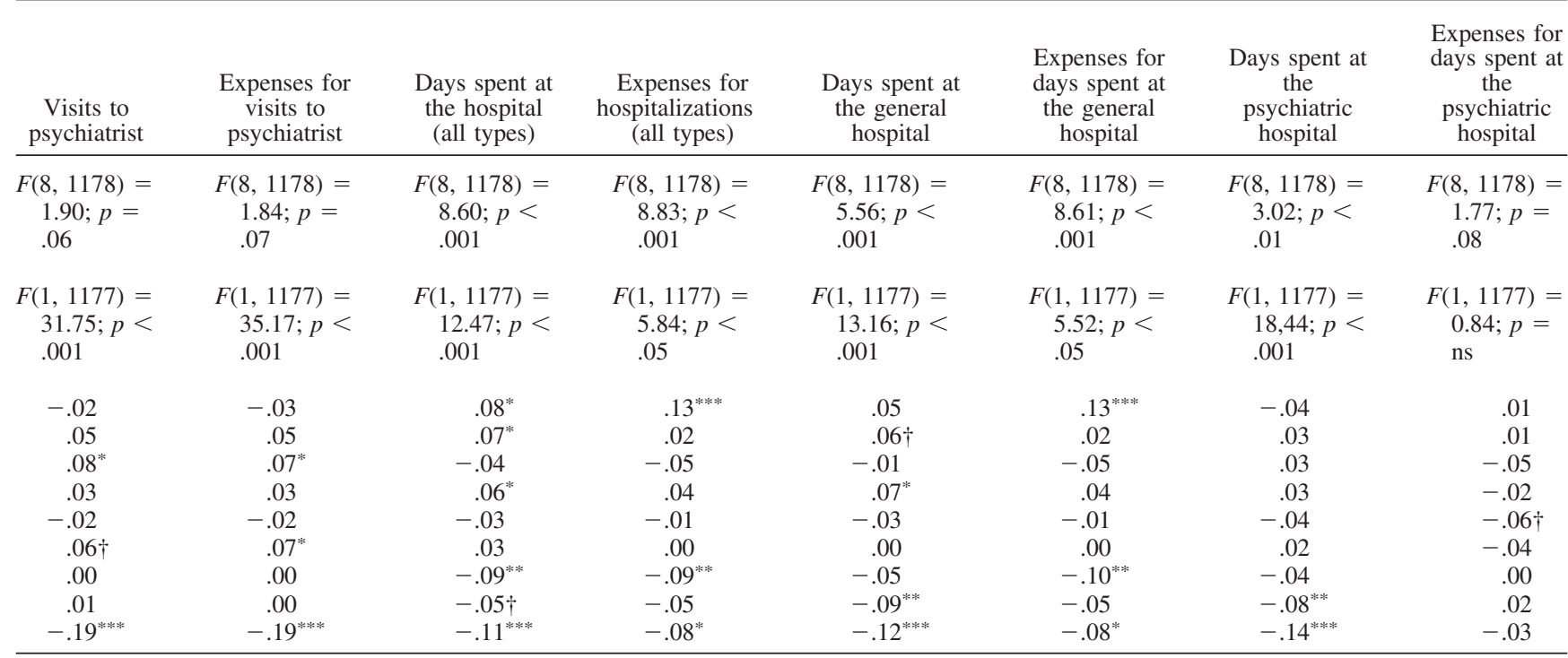

review; for alcohol use, see World Health Organization Alcohol Report, 2011 for review; for Tobacco, see World Health Organization Tobacco Report, 2012 for review). As we expected, emotional competence was also a significant predictor of health outcomes. Given the intercorrelations among predictors, we then performed hierarchical regressions to determine whether $\mathrm{EC}$ has incremental validity to predict health over and above the other predictors. Except for PA and NA (that correlate highly with EC) ${ }^{3}$ all other predictors (EC, age, sex, education, BMI, social support, diet habits, physical activity habits, and tobacco and alcohol habits) were entered in the model. As shown in the "enter" hierarchical regressions summarized in Table 2, EC has incremental validity to predict all objective indicators of health over and above the other predictors (however, it does not have incremental validity to predict the self-reported use of two nonreimbursed health services: alternative medicines and muscular well-being). The $\beta \mathrm{s}$ show that when the influence of all other predictors is held constant, EC remains a significant predictor of 13 (out of 16) indicators of health, age of 10 , sex of 9 , education and physical activity of 6 , BMI of 5 , social support of 4 , and tobacco and alcohol of 2 . These results indicate that EC is a significant, but neglected, predictor of health.

\section{Study 2}

Study 2 first aimed to replicate the results of Study 1 over a larger sample and to clarify the relative weight of the various EC dimensions in the prediction of health. Therefore, a new instrument was used to measure EC. Additionally, Study 2 aimed to examine which variables mediate the effect of EC on health and, finally, determine to what extent EC moderates the effect of already known health predictors.
Participants and procedure. A stratified ${ }^{4}$ sample of 200,000 adults (between 18 and 80 years old) was created and contacted by email by the MC-CM. Participants were invited to complete a Survey on emotions and health. Among this sample, 16,999 subjects answered the whole questionnaire and gave their consent for coupling it with the health data in possession of the MC-CM. Among this sample, 9,616 subjects were members of the MC-CM for the whole period under study (2001-2012). The final sample consisted of these 9,616 subjects $\left(M_{\text {age }}=56.53, S D=13.3 ; 59 \%\right.$

\footnotetext{
${ }^{3}$ The reason why we did not include PA and NA in the regression models is that, as shown in Supplementary Table 1, there is a huge correlation between EC and PA (.66) and NA (-.54). These correlations are expected because, as its name indicates, EC targets the processing of emotions. However, because of these correlations, including PA and NA in the model takes up a lot of the variance explained by EC. This is logical because PA and NA are more proximal variables to health than EC. As we show in our subsequent SEM mediation analyses, emotions mediate the effect of EC on health. Including the mediator in the model always significantly decreases the explanatory power of the independent variable (the significant reduction of the direct effect of the independent variable is even the necessary condition to conclude that there is a significant mediation).

${ }^{4}$ Contrary to Study 1, the proportion of French-speakers versus Dutchspeakers is not representative of the Belgian population in Study 2. The reason is that the MC-CM has the email address of only 35,497 Frenchspeakers (French-speakers are less likely to communicate their email address to the MC-CM than Dutch-speakers). As a result, the proportion of French-speakers contacted by email in Study 2 is only $18 \%$ (vs. $40 \%$ in the Belgian population) and the proportion of Dutch-speakers contacted is $82 \%$ (vs. $60 \%$ in the Belgian population). The sample is fully stratified on the other variables (age, gender, and SES level).
} 
female). As can be seen in the Supplementary Table 3, women, seniors, and Dutch-speakers are overrepresented in the final sample.

\section{Measures.}

Demographics. Participants were asked to indicate their province, age, sex, education level (see Study 1), height, and weight (to compute their BMI).

$\boldsymbol{E C}$ was assessed with the Profile of Emotional Competence (PEC; Brasseur, Grégoire, Bourdu, \& Mikolajczak, 2013). This measure (including 50 items rated from 1 strongly disagree to 5 strongly agree) was especially designed to provide a separate subscore for each emotional competency. It provides 10 subscores (identification of one's emotions, identification of others' emotions, understanding of one's emotions, understanding of others' emotions, expression of one's emotions, listening to others' emotions, regulation of one's emotions, regulation of others' emotions, use of one's emotions, and use of others' emotions), forming three global scores: an intrapersonal EC score $(\alpha=.86)$, an interpersonal EC score $(\alpha=.89)$, and a total EC score $(\alpha=.92)$. Examples of items are "during an argument, I can't identify if I am sad or angry" and "my emotions inform me of what is important to me."

Trait Positive Emotions were measured using eight items rated on a 5-point scale (ranging from never to very often): tranquil, relaxed, at ease, serene, enthusiastic, happy, amazed, and joyful. This scale was designed for the purpose of the current study to represent positive emotions of low and high arousal, respectively (Barrett \& Russell, 1999). Factor analysis confirmed the twofactor structure; together these explain $69 \%$ of the variance. The internal consistency $(\alpha)$ of the scale was .88 (.84 for the "low arousal" PA subscale and .83 for the "high arousal" PA subscale).

Trait Negative Emotions were evaluated using 21 items rated on a 5-point scale (ranging from never to very often), representing low and high arousal levels of the most common negative emotions. Factor analysis revealed that the items formed four factors that we named anxiety-stress, anger, sadness, shame-guilt (explaining together $61 \%$ of the variance) plus one "stand-alone" item: "frustration." The internal consistency of the scale $(\alpha)$ was excellent: .91 (.85 for anxiety-stress, .78 for anger, .84 for sadness, and .74 for shame-guilt).

Social support was appraised as in Study 1. The internal consistency $(\alpha)$ of the scale was .79 .

Health behaviors were assessed as in Study 1. The internal consistency $(\alpha)$ of the scale was .67 (.69 for diet habits and .60 for physical activity habits).

Consumption of nonreimbursed drugs was assessed as in Study 1. As these items were not expected to show high internal consistency, no $\alpha$ was computed.

Objective health care consumption was obtained as in Study 1. We also obtained the total amount of money spent for each subject, all expenses combined (i.e., including emergency calls etc.).

Results and discussion. Table 3 presents the correlations between the various health predictors and both self-reported and objective health outcomes. The first observation is that all correlations (except for the BMI) are weaker than in Study 1. Therefore, we examined if the database of Study 2 differed from that of Study 1 on any relevant criteria. It did on education and age (both higher in Study 2). Because the former is a protective factor and the latter a vulnerability factor (and as they interact in opposite ways with variables of interest), it is unlikely that these differences explained the decrease in the magnitude of the correlations. At the time of writing, we have no explanation for this observation.

Replication of Study 1's findings. Although the correlations are smaller in Study 2, the results globally replicate Study 1's findings: the predictive power of tobacco and alcohol was again lower than expected, but emotional competence (both intrapersonal and interpersonal factors), age, education, BMI, PA, NA, social support, diet habits, physical activity habits were significantly related to drug, and health care consumption. As in Study 1, diet habits did not predict drug consumption after Bonferroni correction. However, contrary to Study 1, sex did not come out as a significant predictor after Bonferroni correction.

Table 4 provides a global overview of the correlation between EC and the total amount of expenses to be borne by the mutual benefit society and by the patient. The results confirm those of Table 3: the higher the EC, the lower the health care expenses for both the mutual benefit society and the patient. Although the correlations may seem weak at first sight, they are nevertheless practically significant: A comparison after a median-split between people with below-average EC ("low EC") and people with aboveaverage EC ("High EC") indicates that the former cost the Mutual Benefit Society approximately 1,985 EUR/year and the second 1,641 EUR/year. Thus, there is a difference of 361 EUR/year between people with levels of $\mathrm{EC}$ below or above the median. If we consider the whole Belgian population $(11,162,000$ inhabitants), the former cost $\sim 2$ billion more per year to the Belgian social security (i.e., 343 EUR $\times 558,100^{5}=1.9$ billion Euros) than the latter. ${ }^{6}$ Small correlations can bear significant consequences.

As in Study 1, we also performed hierarchical regressions ("enter") to determine whether EC has incremental validity to predict health over and above the other predictors. EC, age, sex, education, BMI, social support, diet habits, physical activity habits, and tobacco and alcohol habits were entered in the model. As shown in Table 5, EC has incremental validity to predict all health indicators over and above the other predictors. The $\beta$ s show that when the influence of all other predictors is held constant, age remains a significant predictor of 12 (out of 13) indicators of health, intrapersonal EC, education, and social support of 10, sex of 9, physical activity of 8 , interpersonal EC of 7, BMI of 6, tobacco and alcohol of 5 , and diet habits of 4 . Note that although bivariate correlations between interpersonal EC and health indicators were negative (i.e.,

\footnotetext{
${ }^{5}$ Half of the Belgian population as there is, by definition, only half of the population with a level of EC below the median.

${ }^{6}$ If the $343 \mathrm{EUR} / \mathrm{year}$ figure reflects the true difference between people with a level of EC below versus above the median (as computed directly from the database), the estimation of a difference of 1.9 billion EUR/year for the whole Belgian population constitutes an extrapolation based on several assumptions: (a) the median EC observed in the current study is a good estimator of the median EC of the Belgian population (this assumption is probably correct) and (b) the 10,000 subjects in the database constitute a representative sample of the Belgian population (this is probably not the case, not least because people under 18 years old were not contacted in this study). Note that this estimation does not take into consideration potential extraneous differences between the high versus low EC groups that may account for the reported cost differences (e.g., the level of education). To refine this, a purely econometric article on the financial implication of EC for the social security is in preparation with an economist.
} 


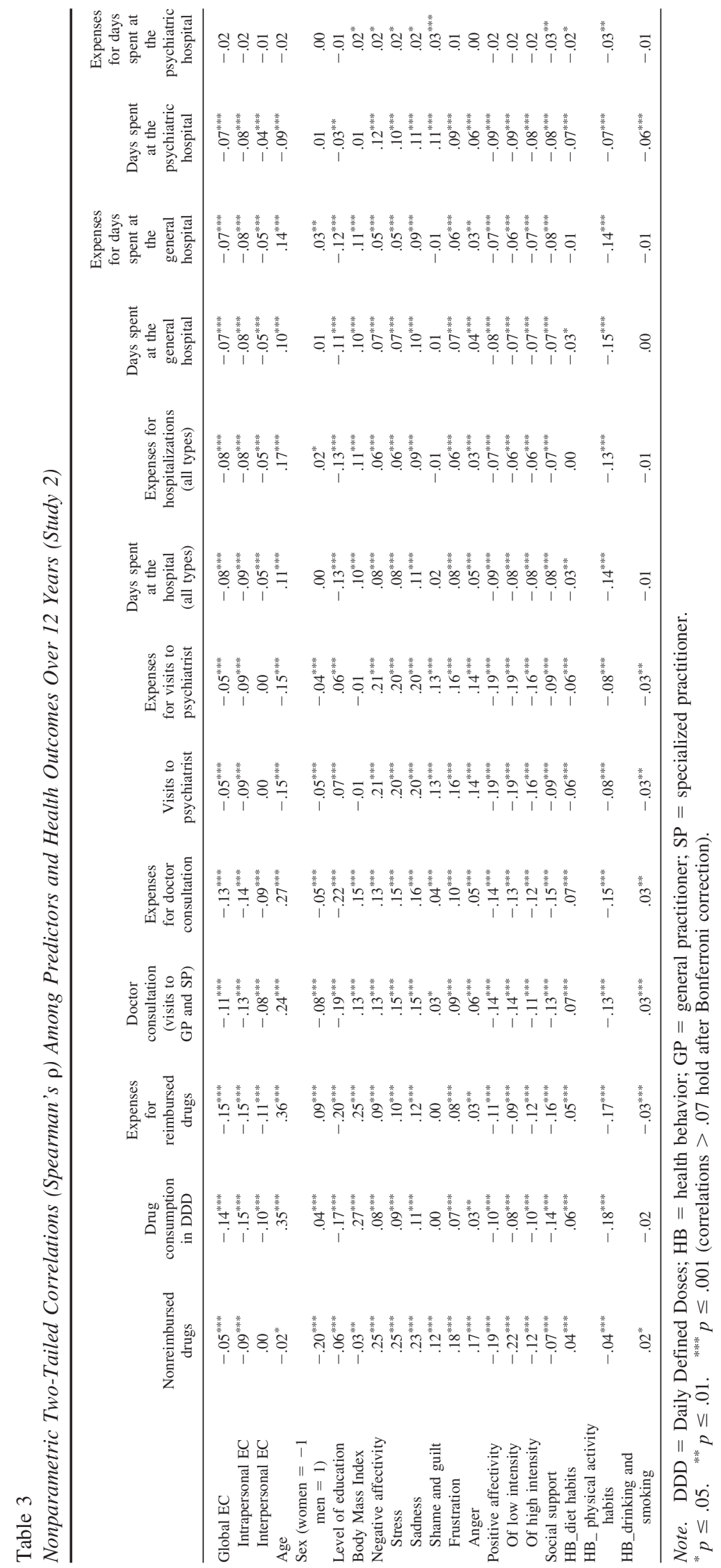


Table 4

Nonparametric Two-Tailed Correlations (Spearman's Rho) Among Predictors and Global Health Expenses Over 12 Years (Study 2)

\begin{tabular}{|c|c|c|c|c|}
\hline & $\begin{array}{l}\text { Expenses for } \\
\text { the MC-CM }\end{array}$ & $\begin{array}{l}\text { Expenses for the } \\
\text { client (user co- } \\
\text { payment) }\end{array}$ & $\begin{array}{c}\text { User } \\
\text { additional } \\
\text { charges }^{\mathrm{a}}\end{array}$ & $\begin{array}{c}\text { Co-payment }+ \\
\text { additional } \\
\text { charges }\end{array}$ \\
\hline Global EC & $-.12^{* * *}$ & $-.11^{* * * *}$ & -.01 & $-.08^{* * *}$ \\
\hline Intrapersonal EC & $-.13^{* * * *}$ & $-.13^{* * * *}$ & $-.04^{* * * *}$ & $-.10^{* * * *}$ \\
\hline Interpersonal EC & $-.09^{* * *}$ & $-.07^{* * * * *}$ & -.01 & $-.04^{* * *}$ \\
\hline Age & $.26^{* * * *}$ & $.25^{\text {***** }}$ & $.14^{* * * * *}$ & $.22^{* * * *}$ \\
\hline $\operatorname{Sex}(\operatorname{men}=1)$ & $.03^{*}$ & $-.03^{* * *}$ & $-.09^{* * * * *}$ & $-.05^{* * *}$ \\
\hline Level of education & $-.18^{* * *}$ & $-.12^{* * * *}$ & $-.02^{*}$ & $-.09^{* * *}$ \\
\hline Body Mass Index & $.16^{* * * *}$ & $.16^{* * * *}$ & $.02^{*}$ & $.12^{* * * *}$ \\
\hline Negative affectivity & $.10^{* * * *}$ & $.11^{* * * *}$ & $.05^{* * * *}$ & $.09^{* * * *}$ \\
\hline Stress & $.11^{* * * * *}$ & $.13^{* * * * *}$ & $.07^{* * * * * *}$ & $.12^{* * * *}$ \\
\hline Sadness & $.13^{* * * *}$ & $.13^{* * * *}$ & $.07^{* * * *}$ & $.12^{* * *}$ \\
\hline Shame and guilt & .01 & .01 & -.02 & .00 \\
\hline Frustration & $.08^{* * * *}$ & $.09^{* * * *}$ & $.03^{* *}$ & $.07^{* * * *}$ \\
\hline Anger & $.05^{* * * *}$ & $.06^{* * * *}$ & $.04^{* * * *}$ & $.06^{* * * *}$ \\
\hline Positive affectivity & $-.12^{* * * *}$ & $-.13^{* * * *}$ & $-.06^{* * * *}$ & $-.12^{* * * *}$ \\
\hline Of low intensity & $-.10^{* * * *}$ & $-.12^{* * * *}$ & $-.07^{* * * *}$ & $-.12^{* * * *}$ \\
\hline Of high intensity & $-.11^{* * *}$ & $-.11^{* * * *}$ & $-.03^{* * *}$ & $-.09^{* * * *}$ \\
\hline Social support & $-.13^{* * *}$ & $-.11^{* * * *}$ & $-.02^{*}$ & $-.08^{* * *}$ \\
\hline HB_diet habits & $.03^{* *}$ & $.04^{* * * * *}$ & $.04^{* * * * *}$ & $.04^{* * *}$ \\
\hline HB_physical activity habits & $-.16^{* * *}$ & $-.15^{* * * * *}$ & $-.06^{* * * *}$ & $-.13^{* * *}$ \\
\hline HB_drinking and smoking & -.01 & -.01 & .01 & .01 \\
\hline
\end{tabular}

Note. $\mathrm{HB}=$ health behaviors.

${ }^{\text {a }}$ User additional charges apply when the patient requires nonreimbursed services (e.g., single room).

${ }^{*} p \leq .05 . \quad{ }^{* *} p \leq .01{ }^{* * *} p \leq .001$.

the higher the interpersonal EC, the lower the health care consumption), hierarchical regression analyses reveal that, when the influence of intrapersonal EC is held constant, the direction of the effect reverses. Therefore, we investigated this further by testing the interaction between intra- and interpersonal EC on health; we discovered that people who have the lowest health care consumption are people with high intrapersonal EC and low interpersonal EC. Future studies will have to go deeper into this but it seems like there might be a cost to being other-oriented.

Differential effect of the various EC facets on health. As indicated earlier, a further aim of Study 2 was to examine which facets of EC are the most predictive of health outcomes. As shown in Table 6, although both factors were significant, intrapersonal emotional competencies were more predictive of health outcomes than interpersonal emotional competencies. Note that only intrapersonal EC was predictive of mental health outcomes (i.e., visits to the psychiatrist; hospitalization in a psychiatric hospital). Among the intrapersonal facets, emotion regulation was the most predictive of mental health outcomes whereas emotion understanding was the most predictive of all other outcomes (drug consumption, doctor consultation, and hospitalization in general hospitals). Among the interpersonal facets, none significantly predicted mental health outcomes whereas three (i.e., identification, understanding, and utilization of others' emotions) significantly predicted the other health outcomes. Among those three, the ability to understand others' emotions was the most predictive.

Differential effect of EC facets on the various drug classes. As indicated in the Supplementary Table 4, EC was not equally predictive of all types of drugs, which suggests that EC may be more specifically related to the functioning of certain body systems than others.
Mediation effects. Structural Equation Modeling (SEM) was performed to determine which variables, if any, mediate the relationship between EC and health. SEM analyses were performed using Maximum Likelihood estimations with AMOS 21 (IBM Inc.). Model fit was assessed using the criteria of $\mathrm{Hu}$ and Bentler (1999) based on the Comparative Fit Index (CFI $\geq .95)$, the Standardized Root Mean Square Residual (SRMR $\leq .08)$, and the Root Mean Square Error of Approximation (RMSEA $\leq .05)$ with its $90 \%$ confidence interval (CI). Mediations were tested using bootstrapping to determine the significance of direct and indirect effects. We report below the 95\% Bias Corrected Confidence Interval. As our sample was large enough to cross-validate the model (Cudeck \& Browne, 1983), we randomly extracted three samples containing each $\sim 50 \%$ of the data (sample $1, n=4853$; sample $2, n=4744$; and sample $3, n=4791)$. The model was developed on Sample 1 (calibration group) and the fit was then tested on Samples 2 and 3 (validation groups). The model that best fitted the data is a model where the effect of EC on health is mediated by NA, PA, social support, and health behaviors (see Figure 1). The goodness of fit of this model was excellent (model fit for calibration sample: $\chi^{2}(89)=1918.25, p \leq .001$, CFI $=$ 0.93, SRMR $=.04$, RMSEA $=0.065(90 \% \mathrm{CI}=.063$ to .068$)$; model fit for the combined sample with no equality constraint imposed: $\chi^{2}(267)=5707.74, p \leq .001, \mathrm{CFI}=0.93, \mathrm{SRMR}=.04$, RMSEA $=0.038(90 \% \mathrm{CI}=.037$ to .038$))$. The model developed on Sample 1 was successfully cross-validated on Samples 2 and 3: constraining the structural paths to be equal across the three samples yielded an excellent fit to the data $\left(\chi^{2}(317)=5730.53\right.$, $p \leq .001, \mathrm{CFI}=0.93, \mathrm{SRMR}=.04, \mathrm{RMSEA}=0.034(90 \% \mathrm{CI}=$ .034 to .035). The difference in $\chi^{2}$ value between models was not statistically significant, $\chi^{2}(50)=22.80, p=1.00$, even when we 


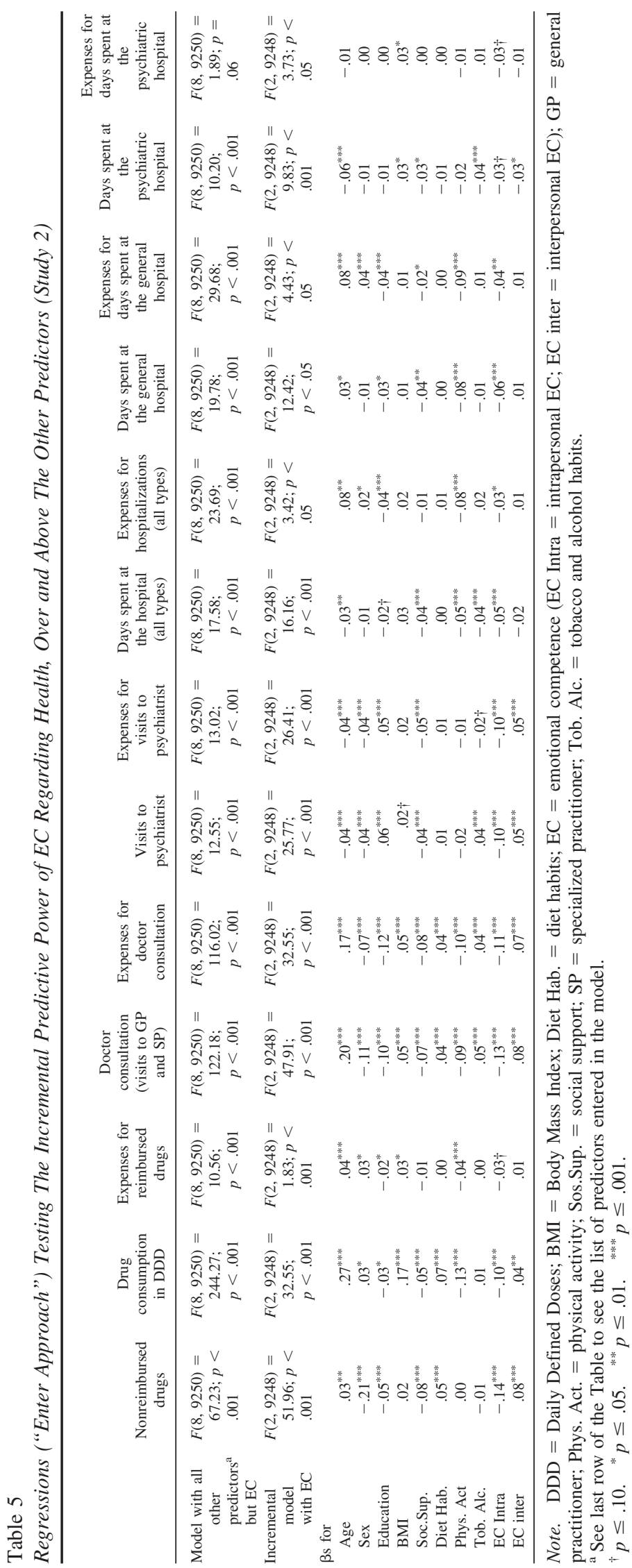


constrained both structural paths and structural weights, $\chi^{2}(30)=$ $12.76, p=.99$ and when we imposed the equality of structural covariances plus the two last constraints, $\chi^{2}(2)=.13, p=.94$.

Therefore, as hypothesized, EC influences health directly, but also indirectly through negative and positive affect, social support and health behaviors. The total effect of emotional competences was significant for the three samples $(\beta=-.18,95 \%$ bootstrap CI $[-.22$ to -.15$] ; \beta=-.17,95 \%$ bootstrap CI $[-.21$ to -.14$]$; $\beta=-.19,95 \%$ bootstrap CI $[-.23$ to -.16$]$, respectively). The direct effect of emotional competences was also significant (except in Sample 2) but lower than the total effect $(\beta=-.06,95 \%$ bootstrap CI [ -.11 to -.01$] ; \beta=-.04,95 \%$ bootstrap CI [-.09 to .01$] ; \beta=-.07,95 \%$ bootstrap $\mathrm{CI}[-.12$ to -.02$]$, respectively) meaning that this effect was partialed out by the mediators. Indeed, for the three samples, we found a significant indirect effect of the mediators, that is, negative affect, positive affect, social support and health behaviors $(\beta=-.13,95 \%$ bootstrap CI $[-.16$ to -.09$] ; \beta=-.14,95 \%$ bootstrap CI $[-.17$ to -.10$] ; \beta=-.12$, $95 \%$ bootstrap CI [ -.16 to -.09$]$, respectively).

Moderation effects. A last aim of Study 2 was to examine whether high EC could moderate the impact of certain known risk factors for health. A systematic test of moderation effect was performed, searching for any significant interaction between EC and age, sex, education, BMI, social support, diet habits, physical activity, and tobacco and alcohol use, respectively. As shown in Table 7, two-thirds of the interactions were significant (three were marginally significant). All interactions involving objective health outcomes are graphically represented and commented in the Supplementary Material [SM] (see Figures SM 1 to 30). Figures SM 2, SM 4, SM 12, and SM 18 are reproduced in Figure 2 because they are particularly representative of the pattern of interactions found. Globally, analyses indicated first that EC moderates the effect of sex, age and BMI on drug consumption. Vulnerable people (men, older adults, and people with higher BMI) take more drugs, as well as people with low EC. However, and this is where the variable interacts, vulnerable people with low EC take significantly more drugs than vulnerable people with high EC (see Figure SM 2). Analyses also indicated that EC moderates the effect of education, BMI, diet habits, and physical activity on doctor visits. The same type of interaction was found: vulnerable people (i.e., people with low education, high BMI, unhealthy diet habits, and low physical activity) with low EC see the doctor more often than vulnerable people with high EC (see Figure SM 4). Analyses then indicated that EC moderated the effect of age, social support, diet habits, physical activity, and smoking and drinking habits on visits to the psychiatrist. The profile of interaction indicated that vulnerable people (young adults, people with low social support, unhealthy diet habits, low physical activity, high tobacco, and alcohol use) consult the psychiatrist more, but only if they have low EC. As shown in Figure SM 12, there was a specific profile of interaction for tobacco and alcohol use, suggesting that low EC in people with high tobacco and alcohol use may actually reduce the propensity to seek the help of a psychiatrist (possibly through denial).

As expected, EC also moderated the effect of age, education, BMI, social support, diet habits, physical activity, and smoking and drinking habits on hospitalizations. Globally, people with high EC are hospitalized less often. The profile of interaction further indicated that vulnerable people (young adults, people with low 


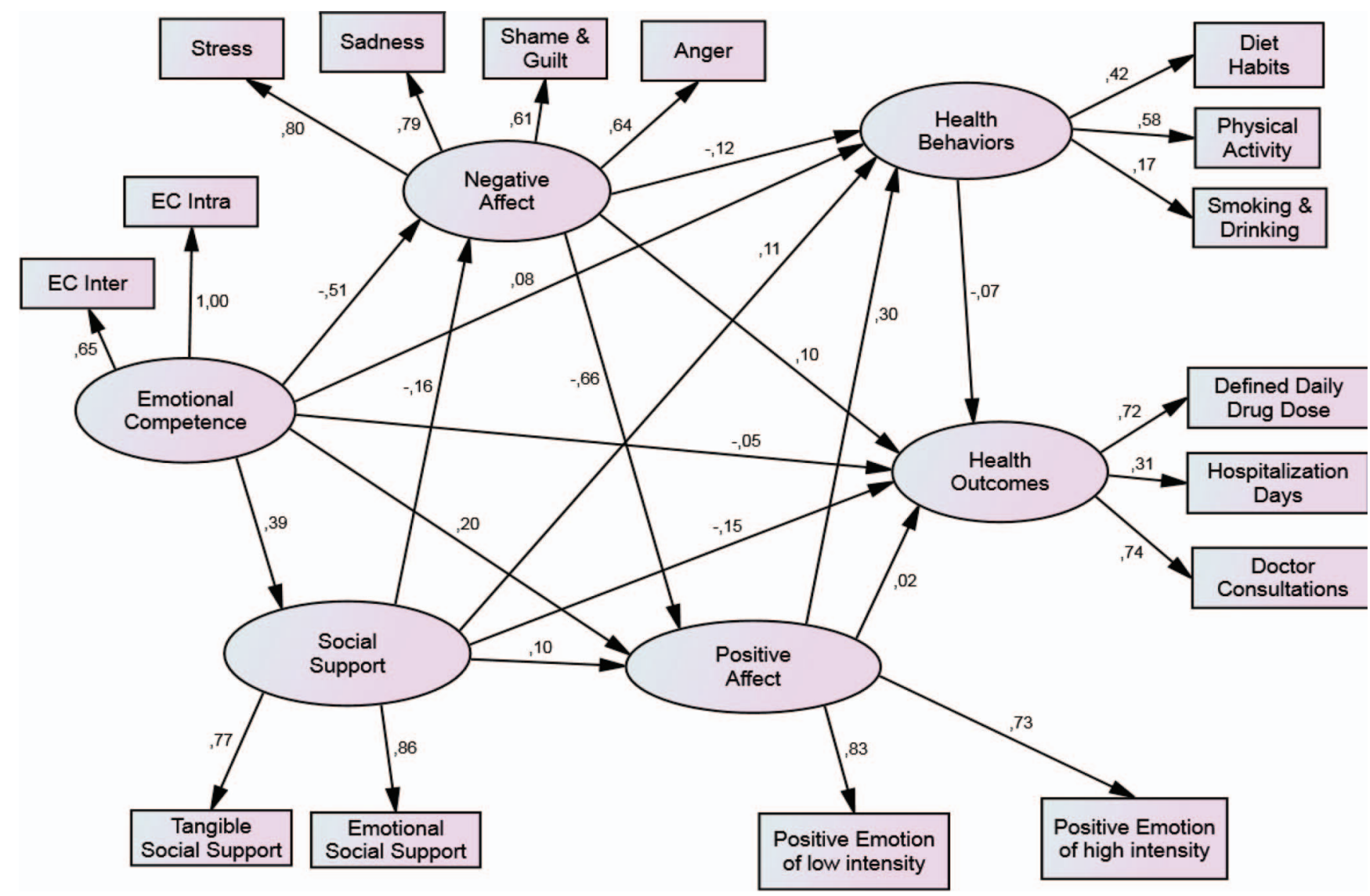

Figure 1. Structural equation model of the relationship between EC and Health in Study 2 (loadings are from calibration sample). See the online article for the color version of this figure.

education, high BMI, low social support, unhealthy diet habits, low physical activity, and high tobacco and alcohol use) spend more days in hospital but only if they have low EC (see, e.g., Figure SM 18). That is, EC attenuates the effect of other risk factors. The profile of interaction for general and psychiatric hospital is roughly the same (see supplementary material).

\section{General Discussion}

Established in the 19th century on a purely biomedical modelhealth is biologically determined-modern medicine's conception was questioned in the 20th century to allow for a biopsychosocial approach. Health then became considered as the product of the interaction of multiple biopsychosocial factors (Engel, 1977). Today's main challenge is to understand how these predictors interact and to identify modifiable predictors, namely, predictors that we can act upon.

As EC can be taught (Kotsou et al., 2011; Nelis et al., 2011), the present research forms part of this approach. It serves a fourfold purpose: (a) to examine the relationship between EC and objective health indicators; (b) to compare the predictive power of EC with other well-known predictors of health such as age, sex, education level, BMI, social support, and health behaviors (diet, physical activity, smoking, and drinking habits); (c) to clarify the relative weight of the various EC dimensions in the prediction of health; and (d) to determine to what extent EC moderates the effect of already known predictors on health.

Results show that EC is a significant predictor of health outcomes and that it predicts incremental variance over and above sex, education, BMI, social support, diet habits, physical activity, and smoking and drinking habits. Given the multiple direct and indirect influences of emotions on health, this finding is not particularly surprising. Indeed, emotions influence health via multiple physiological pathways on the one hand, such as sympathetic (see Kreibig, 2010 for review) or neuroendocrine (Aguilera, Kiss, Luo, \& Akbasak, 1995; Buchanan, al'Absi, \& Lovallo, 1999) activation, inflammation, or immune changes (see Kiecolt-Glaser, McGuire, Robles, \& Glaser, 2002 and Segerstrom \& Miller, 2004 for reviews), DNA damage (Irie, Asami, Nagata, Ikeda, Miyata, \& Kasai, 2001; see Gidron, Russ, Tissarchondou, \& Warner, 2006 for review), and gut permeability (see Collins, 2001), and health behaviors pathways on the other, such as risky behaviors (Cooper, Agocha, \& Sheldon, 2000), emotional eating (Geliebter \& Aversa, 2003), or substance abuse (Cooper, Frone, Russell, \& Mudar, 1995). On the whole, negative emotions have a deleterious impact on health, whereas positive emotions have a protective one (see Salovey, Rothman, Detweiler, \& Steward, 2000 for review). Considering that people with high emotional competencies ex- 


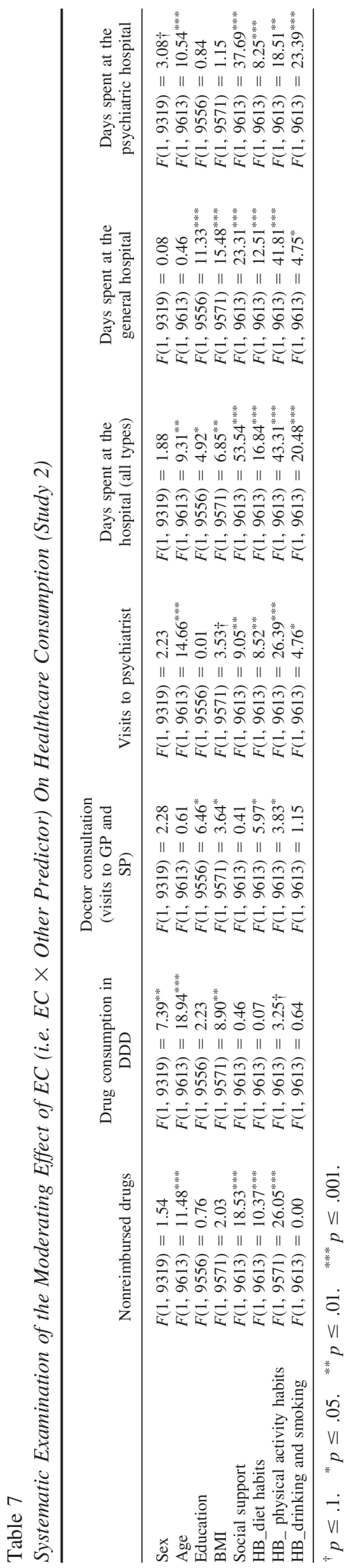

perience more positive and fewer negative emotions (e.g., Brasseur et al., 2013), less physiological activation in negative conditions (e.g., Mikolajczak, Roy, Luminet, Fillée, \& de Timary, 2007) and fewer health damaging behaviors (Brackett, Mayer, \& Warner, 2004), the effects observed in this study were expected. Future research should complement these findings by measuring in the same study, not only EC and health care consumption, but also all the abovementioned pathways (with measures of sympathetic and endocrine activation, inflammation and immunity, DNA damage, gut permeability, and health behaviors). This would allow more precise modeling of the route between EC and health.

Although the main hypothesis of this study was supported, correlations are admittedly small in magnitude. This is likely because of two factors: the measurement error of emotional competence (that was measured by questionnaire) and the number and diversity of the predictors of health. As pointed out above, health is the product of numerous interacting predictors, ranging from the biological and psychological to the social and environmental. Each predictor alone can, therefore, explain only a small portion of the variance. Nevertheless, it is noteworthy that small does not mean trivial. On the basis of the figures reported in the Results section, the population with below-average EC cost annually nearly 2 billion more to the Belgian social security than the population with above-average EC. Knowing that Belgium is a small country of only about 11 million people, the consequences reported on a European scale (739 million people) would be everything but trivial. Small correlations can translate into huge numbers.

The importance of EC regarding health is in contrast to the lack of interest of governments for EC and with the dearth of health promotion actions targeting EC. So far, governments (at least Western ones) have mainly focused on three predictors: physical activity, diet habits, and alcohol and tobacco consumption. The current research suggests that emotion and stress management may represent the much needed and so far missing dimension. Inasmuch as physical activity and healthy diet habits are taught in schools and as children/adolescents are advised against smoking and drinking, one could imagine integrating the development of emotional competences in the school curriculum. The other channels by which health is usually promoted (radio, TV, and leaflets in doctors' waiting rooms) could also be used for older generations.

Beyond its practical implications, this research also adds to the literature on emotion and health. The examination of the relative importance of the various EC dimensions in the prediction of health first confirms that two dimensions already brought to light by research on alexithymia ${ }^{7}$ - the ability to identify and express one's emotion-are indeed significant

\footnotetext{
${ }^{7}$ Alexithymia is a multifaceted construct comprising (a) a difficulty in identifying feelings as well as distinguishing between feelings and the bodily sensations of emotional arousal; (b) a difficulty in describing feelings to others; (c) a restricted imagination, as evidenced by a paucity of fantasies; and (d) a cognitive style that is literal, utilitarian, and externally oriented (Taylor \& Bagby, 2000). There is a large body of evidence showing that alexithymia is associated with a number of psychiatric and psychosomatic disorders (for overviews, see Corcos \& Speranza, 2003; Lumley \& Wehmer, 1996).
} 


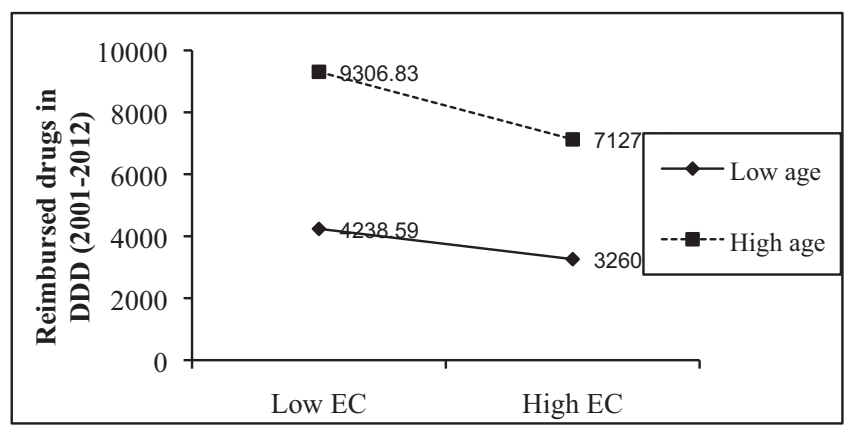

Figure SM 2. Age x EC interaction on reimbursed drugs (in DDD)

Over 12 years, an old adult with low EC has taken 2180 more doses [180 more on an annual basis] than an old adult with high EC (the difference in young adults is 979 doses).

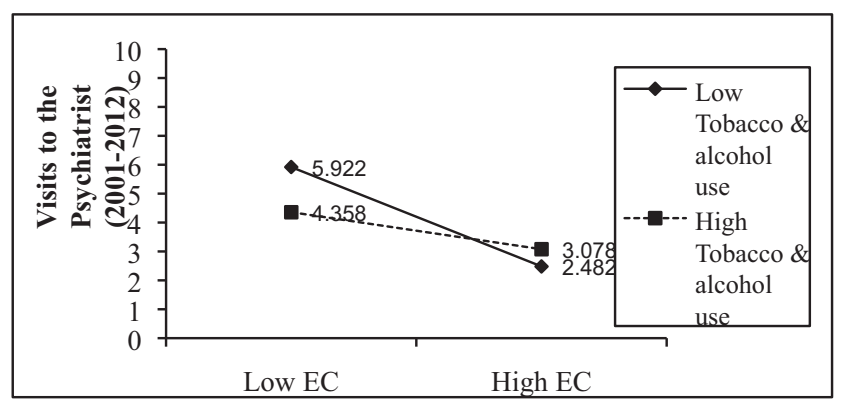

Figure SM 12. Tobaco and alcohol use $x$ CE interaction on visits to the psychiatrist

This graph suggests that low EC may increase denial in substance users and, therefore, reduce their propensity to seek help.

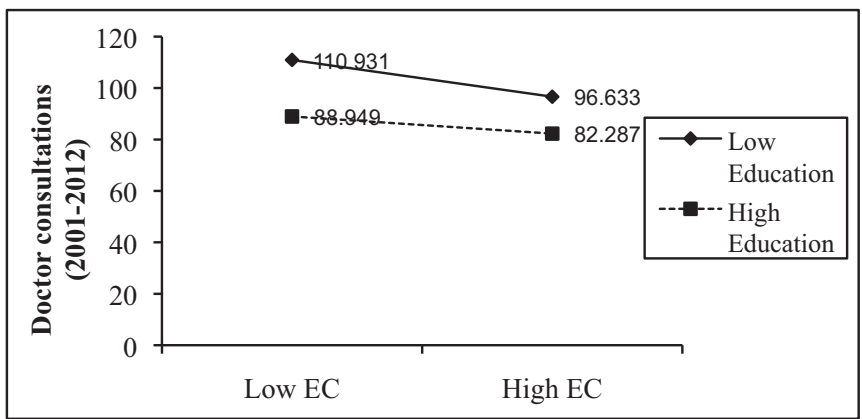

Figure SM 4. Education x CE interaction on doctor consultations (GP \& SP) A person with low education and low EC has consulted the doctor 14 more times than a person with low education and High EC (the difference for people with high education is 7 times).

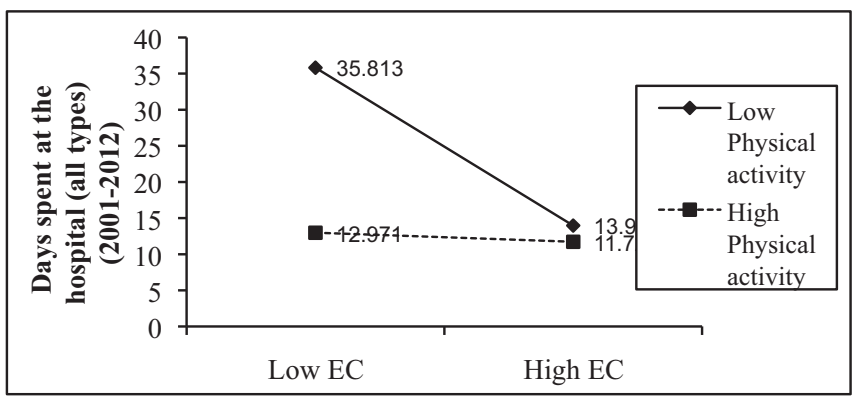

Figure SM 18. Physical activity $x$ CE interaction on days spent at the hospital A person with low physical activity (PA) and low EC has spent 22 more days at the hospital than a person with low PA and high EC (the difference for people with high PA is 1 day). $\rightarrow$ High EC compensates for low physical activity.

Figure 2. Examples of interaction effects of emotional competence with known predictors of health outcomes

(Study 2).

predictors of health outcomes (see, e.g., Lumley \& Norman, 1996). It also indicates that the ability to regulate one's emotions, which has been thought-but not yet shown-to be related to health is indeed predictive of health outcomes. Whereas it was by far the most predictive dimension of mental health outcomes (consumption of psychotropic drugs [i.e., ATC class N], visits to the psychiatrist, days spent at the psychiatric hospital) and of self-reported indicators (i.e., consumption of nonreimbursed drugs), it was not the most predictive dimensions of physical health outcomes, as explained below.

The most predictive dimension of physical health outcomes was the ability to understand one's emotions. This dimension refers to the ability to understand why we feel what we feel and to understand the message conveyed by emotions (e.g., in terms of unsatisfied needs). It is interesting that this dimension turns out to be the most predictive of physical health outcomes because this branch has clearly been the least researched so far in the literature on emotional intelligence or emotional competence or even emotions in general. Although there is a whole field of research on emotion identification (i.e., alexithymia; see Taylor, 2004 for a review of 25 years of research), emotion expression (alexithymia; emotional disclosure; see Pennebaker, 2012 for a synthesis), and emotion regulation (see Gross, 2007 for an overview), there is no such line of research on emotion understanding or emotion utilization. The current results clearly suggest that these dimensions, at least that of emotion under- standing, deserve greater attention and interest. Future research will not only need to uncover the antecedent and consequences of low versus high levels of emotion understanding but, most importantly, it will have to specify the processes (i.e., mechanisms) through which it exerts its effects.

Although informative, the current results suffer from some limitations. The first lies in the fact that, albeit objective, health care consumption is an indirect indicator of health status. Some people (e.g., homeless) are in very bad health condition but do not consult doctors. Others are in objectively good health but overuse health care (because of a need for attention, hypochondria, etc.). Fortunately, the former constitute only a minority of people (probably not represented in our sample) as the social security system in Belgium makes health care easily accessible. The latter may be over represented in our sample and this should be kept in mind when interpreting the results. The second limitation concerns the direction of the effects. Because these results are correlative, it cannot be excluded that the causality between EC and health is bidirectional. Although it is true that the level of health may possibly influence the level of emotional competence and that the relationship may be circular, experimental studies indicate that there is a causal relationship at least between emotional competence and health. Indeed, increasing the level of emotional competence (e.g., via EC training) leads to a reduction of stress hormones and somatic complaints (Kotsou et al., 2011; Nelis et al., 2011). The third 
limitation concerns the increased risk of Type I error because of multiple comparisons. Although we used Bonferroni correction to help us identify truly significant correlations, it is still possible that some correlations are because of chance.

\section{Concluding Comment}

In conclusion, health is the product of multiple factors in constant interaction. Identifying the strongest predictors and, more particularly, those that we can act upon is one of the major challenges of the 21 st century. This study contributes to this endeavor by showing that EC is a neglected but nonetheless important predictor of health. Because it can attenuate (and sometimes even compensate for) the impact of other risk factors, it certainly deserves greater interest and attention. This is particularly the case because EC can be taught and enhanced.

\section{References}

Adler, N. E., Boyce, T., Chesney, M. A., Cohen, S., Folkman, S., Kahn, R. L., \& Syme, S. L. (1994). Socioeconomic status and health. The challenge of the gradient. American Psychologist, 49, 15-24. http://dx .doi.org/10.1037/0003-066X.49.1.15

Aguilera, G., Kiss, A., Luo, X., \& Akbasak, B. S. (1995). The renin angiotensin system and the stress response. Annals of the New York Academy of Sciences, 771, 173-186. http://dx.doi.org/10.1111/j.17496632.1995.tb44679.x

Austin, E. J., Saklofske, D. H., \& Egan, V. (2005). Personality, well-being and health correlates of trait emotional intelligence. Personality and Individual Differences, 38, 547-558. http://dx.doi.org/10.1016/j.paid .2004 .05 .009

Barrett, L. F., \& Russell, J. A. (1999). The structure of current affect controversies and emerging consensus. Current Directions in Psychological Science, 8, 10-14. http://dx.doi.org/10.1111/1467-8721.00003

Bertakis, K. D., Azari, R., Helms, L. J., Callahan, E. J., \& Robbins, J. A. (2000). Gender differences in the utilization of health care services. The Journal of Family Practice, 49, 147-152.

Brackett, M. A., Mayer, J. D., \& Warner, R. M. (2004). Emotional intelligence and its relation to everyday behaviour. Personality and Individual Differences, 36, 1387-1402. http://dx.doi.org/10.1016/ S0191-8869(03)00236-8

Brasseur, S., Grégoire, J., Bourdu, R., \& Mikolajczak, M. (2013). The Profile of Emotional Competence (PEC): Development and validation of a self-reported measure that fits dimensions of emotional competence theory. PLOS ONE, 8, e62635. http://dx.doi.org/10.1371/journal.pone .0062635

Buchanan, T. W., al'Absi, M., \& Lovallo, W. R. (1999). Cortisol fluctuates with increases and decreases in negative affect. Psychoneuroendocrinology, 24, 227-241. http://dx.doi.org/10.1016/S0306-4530(98)00078-X

Collins, S. M. (2001). Stress and the Gastrointestinal Tract IV. Modulation of intestinal inflammation by stress: Basic mechanisms and clinical relevance. American Journal of Physiology. Gastrointestinal and Liver Physiology, 280, G315-G318.

Cooper, M. L., Agocha, V. B., \& Sheldon, M. S. (2000). A motivational perspective on risky behaviors: The role of personality and affect regulatory processes. Journal of Personality, 68, 1059-1088. http://dx.doi .org/10.1111/1467-6494.00126

Cooper, M. L., Frone, M. R., Russell, M., \& Mudar, P. (1995). Drinking to regulate positive and negative emotions: A motivational model of alcohol use. Journal of Personality and Social Psychology, 69, 990-1005. http://dx.doi.org/10.1037/0022-3514.69.5.990

Cooper, A., \& Petrides, K. V. (2010). A psychometric analysis of the Trait Emotional Intelligence Questionnaire-Short Form (TEIQue-SF) using
Item Response Theory. Journal of Personality Assessment, 92, 449457.

Corcos, M., \& Speranza, M. (2003). Psychopathologie de l'alexithymie. Paris: Dunod.

Cudeck, R., \& Browne, M. W. (1983). Cross-validation of covariance structures. Multivariate Behavioral Research, 18, 147-167. http://dx.doi .org/10.1207/s15327906mbr1802_2

Engel, G. L. (1977). The need for a new medical model: A challenge for biomedicine. Science, 196, 129-136. http://dx.doi.org/10.1126/science .847460

Geliebter, A., \& Aversa, A. (2003). Emotional eating in overweight, normal weight, and underweight individuals. Eating Behaviors, 3, 341347. http://dx.doi.org/10.1016/S1471-0153(02)00100-9

Gidron, Y., Russ, K., Tissarchondou, H., \& Warner, J. (2006). The relation between psychological factors and DNA-damage: A critical review. Biological Psychology, 72, 291-304. http://dx.doi.org/10.1016/j .biopsycho.2005.11.011

Gross, J. J. (2007). Handbook of emotion regulation. New York, NY: Guilford Press.

Hu, L. T., \& Bentler, P. M. (1999). Cutoff criteria for fit indexes in covariance structure analysis: Conventional criteria versus new alternatives. Structural Equation Modeling: A Multidisciplinary Journal, 6, $1-55$.

Irie, M., Asami, S., Nagata, S., Ikeda, M., Miyata, M., \& Kasai, H. (2001). Psychosocial factors as a potential trigger of oxidative DNA damage in human leukocytes. Japanese Journal of Cancer Science, 92, 367-376. http://dx.doi.org/10.1111/j.1349-7006.2001.tb01104.x

Kiecolt-Glaser, J. K., McGuire, L., Robles, T. F., \& Glaser, R. (2002). Emotions, morbidity, and mortality: New perspectives from psychoneuroimmunology. Annual Review of Psychology, 53, 83-107. http://dx.doi .org/10.1146/annurev.psych.53.100901.135217

Kotsou, I., Nelis, D., Grégoire, J., \& Mikolajczak, M. (2011). Emotional plasticity: Conditions and effects of improving emotional competence in adulthood. Journal of Applied Psychology, 96, 827-839. http://dx.doi .org/10.1037/a0023047

Kreibig, S. D. (2010). Autonomic nervous system activity in emotion: A review. Biological Psychology, 84, 394-421. http://dx.doi.org/10.1016/ j.biopsycho.2010.03.010

Lumley, M. A., \& Norman, S. (1996). Alexithymia and health care utilization. Psychosomatic Medicine, 58, 197-202. http://dx.doi.org/ 10.1097/00006842-199605000-00001

Martins, A., Ramalho, N., \& Morin, E. (2010). A comprehensive metaanalysis of the relationship between emotional intelligence and health. Personality and Individual Differences, 49, 554-564. http://dx.doi.org/ 10.1016/j.paid.2010.05.029

Mayer, J. D., \& Salovey, P. (1997). What is emotional intelligence. In P. Salovey \& D. Sluyter (Eds.), Emotional development and emotional intelligence: Educational implications (pp. 3-31). New York, NY: Basic Books.

Mikolajczak, M., Menil, C., \& Luminet, O. (2007). Explaining the protective effect of trait emotional intelligence regarding occupational stress: Exploration of emotional labor processes. Journal of Research in Personality, 41, 1107-1117. http://dx.doi.org/10.1016/j.jrp.2007.01.003

Mikolajczak, M., Petrides, K. V., Coumans, N., \& Luminet, O. (2009). The moderating effect of trait emotional intelligence on mood deterioration following laboratory-induced stress. International Journal of Clinical and Health Psychology, 9, 455-477.

Mikolajczak, M., Petrides, K. V., \& Hurry, J. (2009). Adolescents choosing self-harm as an emotion regulation strategy: The protective role of trait emotional intelligence. British Journal of Clinical Psychology, 48, 181193. http://dx.doi.org/10.1348/014466508X386027

Mikolajczak, M., Quoidbach, J., Kotsou, I., \& Nelis, D. (2009). Les compétences émotionnelles. Paris: Dunod. 
Mikolajczak, M., Roy, E., Luminet, O., Fillée, C., \& de Timary, P. (2007). The moderating impact of emotional intelligence on free cortisol responses to stress. Psychoneuroendocrinology, 32, 1000-1012. http://dx .doi.org/10.1016/j.psyneuen.2007.07.009

Nelis, D., Kotsou, I., Quoidbach, J., Hansenne, M., Weytens, F., Dupuis, P., \& Mikolajczak, M. (2011). Increasing emotional competence improves psychological and physical well-being, social relationships, and employability. Emotion, 11, 354-366. http://dx.doi.org/10.1037/ a0021554

O'Boyle, E. H., Jr., Humphrey, R. H., Pollack, J. M., Hawver, T. H., \& Story, P. A. (2011). The relation between emotional intelligence and job performance: A meta-analysis. Journal of Organizational Behavior, 32, 788-818. http://dx.doi.org/10.1002/job.714

Pennebaker, J. W. (2012). Opening up: The healing power of expressing emotions. New York, NY: Guilford Press.

Petrides, K. V., Frederickson, N., \& Furnham, A. (2004). The role of trait emotional intelligence in academic performance and deviant behavior at school. Personality and Individual Differences, 36, 277-293. http://dx .doi.org/10.1016/S0191-8869(03)00084-9

Petrides, K. V., \& Furnham, A. (2003). Trait emotional intelligence: Behavioural validation in two studies of emotion recognition and reactivity to mood induction. European Journal of Personality, 17, 39-57. http://dx.doi.org/10.1002/per.466

Petrides, K. V., Pérez-González, J. C., \& Furnham, A. (2007). On the criterion and incremental validity of trait emotional intelligence. Cognition and Emotion, 21, 26-55. http://dx.doi.org/10.1080/ 02699930601038912

Pressman, S. D., \& Cohen, S. (2005). Does positive affect influence health? Psychological Bulletin, 131, 925-971.

Repetto, L., \& Audisio, R. A. (2006). Elderly patients have become the leading drug consumers: It's high time to properly evaluate new drugs within the real targeted population. Journal of Clinical Oncology, 24, e62-e63. http://dx.doi.org/10.1200/JCO.2006.09.3039

Riley, H., \& Schutte, N. S. (2003). Low emotional intelligence as a predictor of substance-use problems. Journal of Drug Education, 33, 391-398. http://dx.doi.org/10.2190/6DH9-YT0M-FT99-2X05

Salovey, P., Rothman, A. J., Detweiler, J. B., \& Steward, W. T. (2000). Emotional states and physical health. American Psychologist, 55, 110121. http://dx.doi.org/10.1037/0003-066X.55.1.110

Sarason, I. G., Levine, H. M., Basham, R. B., \& Sarason, B. R. (1983). Assessing social support: The social support questionnaire. Journal of Personality and Social Psychology, 44, 127-139. http://dx.doi.org/ 10.1037/0022-3514.44.1.127

Schutte, N. S., Malouff, J. M., Bobik, C., Coston, T. D., Greeson, C., Jedlicka, C., . . . Wendorf, G. (2001). Emotional intelligence and interpersonal relations. The Journal of Social Psychology, 141, 523-536. http://dx.doi.org/10.1080/00224540109600569
Schutte, N. S., Malouff, J. M., Thorsteinsson, E. B., Bhullar, N., \& Rooke, S. E. (2007). A meta-analytic investigation of the relationship between emotional intelligence and health. Personality and Individual Differences, 42, 921-933. http://dx.doi.org/10.1016/j.paid.2006.09.003

Segerstrom, S. C., \& Miller, G. E. (2004). Psychological stress and the human immune system: A meta-analytic study of 30 years of inquiry. Psychological Bulletin, 130, 601-630.

Stevens, J., Cai, J., Pamuk, E. R., Williamson, D. F., Thun, M. J., \& Wood, J. L. (1998). The effect of age on the association between body-mass index and mortality. The New England Journal of Medicine, 338, 1-7. http://dx.doi.org/10.1056/NEJM199801013380101

Suls, J., \& Bunde, J. (2005). Anger, anxiety, and depression as risk factors for cardiovascular disease: The problems and implications of overlapping affective dispositions. Psychological Bulletin, 131, 260-300.

Taylor, G. J. (2004). Alexithymia: Twenty-five years of theory and research. In I. Nyklicek, L. Temoshok, \& A. Vingerhoets (Eds.), Emotional expression and health: Advances in theory, assessment and clinical applications. Andover, United Kingdom: Brunner-Routledge.

Taylor, G. J., \& Bagby, R. M. (2000). An overview of the alexithymia construct. In R. Bar-On and J. D. A. Parker (Eds.). The handbook of emotional intelligence: Theory, development, assessment, and application at home, school, and in the workplace (pp. 40-67). San Francisco, CA, US: Jossey-Bass.

Tillmann, T., Krishnadas, R., Cavanagh, J., \& Petrides, K. V. (2013). Possible rheumatoid arthritis subtypes in terms of rheumatoid factor, depression, diagnostic delay and emotional expression: An exploratory case-control study. Arthritis Research \& Therapy, 15, R45. http://dx.doi .org/10.1186/ar4204

Uchino, B. N. (2006). Social support and health: A review of physiological processes potentially underlying links to disease outcomes. Journal of Behavioral Medicine, 29, 377-387. http://dx.doi.org/10.1007/s10865006-9056-5

Warburton, D. E., Nicol, C. W., \& Bredin, S. S. (2006). Health benefits of physical activity: The evidence. Canadian Medical Association Journal, 174, 801-809. http://dx.doi.org/10.1503/cmaj.051351

Watson, D., Clark, L. A., \& Tellegen, A. (1988). Development and validation of brief measures of positive and negative affect: The PANAS scales. Journal of Personality and Social Psychology, 54, 1063-1070. http://dx.doi.org/10.1037/0022-3514.54.6.1063

World Health Organization. (2011). Global status report on alcohol and health. Geneva: World Health Organization.

World Health Organization. (2012). WHO Global Report: Mortality attributable to tobacco. Geneva: World Health Organization.

Received February 25, 2014

Revision received September 30, 2014

Accepted October 6, 2014 